\title{
LA FORMACIÓN HUMANA, FUNDAMENTO DE TODA LA FORMACIÓN SACERDOTAL
}

\author{
JUAN MARÍA URIARTE \\ Obispo de SAN SEbastián
}

DOI: https://doi.org/10.52039/seminarios.v54i189-190.520

Introducción (30); I. El sentido, el enfoque, la orientación (30); 1. El sentido de una frase capital (30); 2. Un enfoque entre varios posibles y legítimos (32); 3. Abrir pistas en un bosque inabarcable (34) II. El impacto sociocultural: oportunidades, dificultades, recursos (34); 1. Cultura y narcisismo (34); a) Apuntes descriptivos (35); b) Repercusiones en la vida presbiteral (35); c) Algunos recursos (36) 2. Cultura y erotismo (37); a) La explosión sexual (A. Berge) (37) b) El erotismo ambiental (37); c) La vida célibe en este contexto (38); d) Para aprender el lenguaje célibe del amor (39); 3. Cultura y pertenencia (38) a) El sentido de pertenencia (39); b) La crisis del sentido de pertenencia (40); c) Pertenencia y vida presbiteral (41); 4. Cultura y confianza básica (E. Erikson) (43); a) Un déficit paradójico (43); b) Confianza básica y vida presbiteral (44); c) Aprender a confiar (44); III. Resortes básicos para una adecuada formación humana (45); 1. Asumir la propia historia (45); 2. Garantizar el equilibrio entre interioridad y exterioridad (47); 3. Una buena dialéctica entre la persona y su rol (48); Conclusión (49). 


\section{INTRODUCCIÓN}

Con alegría y gratitud participo en este Simposio que la Hermandad de Sacerdotes Operarios organiza, en el centenario de la muerte de su Fundador Beato Manuel Domingo y Sol, con el laudable propósito de contribuir a una mayor recepción en la Iglesia de la Exhortación Apostólica Postsinodal Pastores Dabo Vobis (PDV). El interés del tema y mi estrecha familiaridad con los convocantes me han inducido a aceptar su invitación. Los participantes sabrán disculpar las limitaciones de mi intervención, entrecortada con demasiada frecuencia por el ajetreo de una vida episcopal.

Distribuiré mi exposición en tres capítulos. En el primero delinearé el sentido, el enfoque y la orientación de mi conferencia. En el segundo recogeré las oportunidades y dificultades que algunos caracteres mayores de nuestra cultura ofrecen a la formación humana de los sacerdotes y la manera de acogerlas o sortearlas. En el tercero sugeriré algunas líneas formativas preferentes, de carácter global, postuladas por la naturaleza misma del crecimiento humano de los presbíteros presentes y futuros en las actuales circunstancias.

La conferencia está redactada sobre todo con la mirada puesta en los sacerdotes. No les será difícil la trasposición a los seminaristas. Prepárense para un largo itinerario. Espero que el guión les ayude.

\section{EL SENTIDO, EL ENFOQUE Y LA ORIENTACIÓN}

\section{El sentido de una frase capital}

a) Una expresión llamativa

PDV 43 nos dice: «Sin una adecuada formación humana, toda la formación sacerdotal estaría privada de su fundamento necesario». Estamos ante una afirmación fuerte que requiere ser interpretada cuidadosamente.

La frase no significa que la gracia de Cristo no pueda construir sobre un material humano deficiente una vida altamente evangélica. La historia de muchos santos humanamente deficitarios desmiente categóricamente tal interpretación. Lo decisivo no es la neurosis, sino lo que uno hace de su neurosis, nos decía un eminente profesor de Lovaina. No hemos de olvidar, con todo, que, de ley ordinaria, cuando la patología afecta gravemente al núcleo mismo del sujeto humano, el progreso teologal de la persona es, al menos, más difícilmente perceptible. 
b) Un equívoco a disipar

Tanto nuestra concreta condición humana como la entera actividad formativa que se despliega sobre ella, distan de ser puramente naturales. La naturaleza realmente existente, aunque herida e internamente dividida (cfr. Rm 7), está impregnada de la gracia sanante de Cristo. La formación que llamamos humana no es tampoco puramente natural, sino bañada por la acción del Espíritu. En consecuencia, la frase que comentamos no puede entenderse en el contexto de viejos esquemas teológicos ya periclitados que, en su afán de distinguir, corrían el riesgo de separar naturaleza y gracia y hacerlas mutuamente extrañas. La gracia no es un segundo piso que se construye sobre el primer piso de la naturaleza humana real e histórica.

\section{c) La afirmación en positivo}

La palabra fundamento, clave de esta frase, significa en este lugar que la humanidad concreta del sacerdote, cultivada en sus dimensiones huma-nas, es el asiento (el humus) connatural de las demás dimensiones de su formación. No un asiento inerte, sino a la vez activo y receptivo. No una simple pista pasiva de aterrizaje ni un mero soporte. Esta interactividad está reclamando que la formación en las otras dimensiones no sea un aditamento superpuesto, sino arraigado en el fondo humano de la persona, en su corazón, en su mentalidad, en su afectividad, en su voluntad. Los hombres que no encuentran placer en la virtud, no podrán perseverar (Sto. Tomás). Esta complicidad de la dimensión humana con las demás dimensiones asegura la unidad interior (siempre dialéctica e inacabada) de la persona del presbítero.

La experiencia nos ha enseñado a los aquí presentes que una formación teológica académicamente impecable, unas prácticas espirituales asiduas y unas actividades pastorales adecuadas no aseguran sin más la solidez del edificio de una opción sacerdotal. En bastantes ocasiones hemos visto derrumbarse sin mucho dramatismo tal edificio como una construcción artificial que no había echado raíces en el fondo endotímico de la persona, en la carne y sangre de su ser. El presbítero tenía razones para serlo, pero no motivos auténticos para perseverar. La formación no había reconfigurado el deseo humano del presbítero. Remodelar y reorientar nuestros deseos humanos es tal vez la tarea más delicada de nuestra formación.

Así entiendo la afirmación que da título a esta conferencia. 


\section{Un enfoque entre varios posibles}

La formación humana de los presbíteros puede abordarse desde ópticas diferentes, previstas y avaladas por el texto de PDV.

a) Una sería la óptica de la madurez humana. Parte de la convicción de que la formación humana es un itinerario de maduración de la personalidad. Enumera y describe los rasgos que componen la madurez humana e identifica los recursos educativos para ir aproximándose a ella en el decurso formativo previo y posterior a la ordenación. PDV 43, 44 y 72 legitiman esta aproximación. Los planes de formación sacerdotal elaborados por episcopados de diversos países siguen este camino. Véanse, por ejemplo, el n. 91 del italiano y los nn. 48-60 del español. Personalmente he intentado este acercamiento en una conferencia pronunciada el año 2005 en este mismo Colegio1.

b) Una segunda óptica centra su atención en el recorrido biográfico del presbítero. Describe el perfil de las diferentes fases de la vida presbiteral y detecta las posibilidades, las dificultades y los medios formativos disponibles en cada una de ellas. PDV ofrece explícita cobertura a esta vía en los nn. 76 y 77. La Comisión Episcopal para el Clero publicó, el año 2004, una aproximación que esbocé siguiendo esta óptica 2.

c) Un tercer enfoque subraya el impacto que nuestras condiciones socioculturales provocan en la vida y ministerio de los presbíteros. Parte de una somera descripción de algunos rasgos socioculturales dominantes para incidir en sus repercusiones sobre la mentalidad, la sensibilidad, el ánimo vital, las actitudes y los comportamientos sacerdotales. Identifica las oportunidades y los obstáculos que estos rasgos entrañan para la formación humana. Señala los surcos y las insistencias postuladas por dicha formación en el contexto presente.

d) Los textos inspiradores: Mi exposición de hoy va a asomarse, de manera elemental y fragmentaria, a este enfoque que no

\footnotetext{
1 Ha sido publicado en la revista "Seminarios», 2007, págs. 61-90, precedida y prologada por unos breves apuntes sobre la personalidad humana de San Francisco Javier.

2 «La formación sacerdotal permanente», Madrid 2004. EDICE, págs. 241254 y $350-371$.
} 
es en absoluto ajeno a PDV, 5-10 y que está incorporado al título mismo de la Exhortación Papal: «La formación de los sacerdotes en la situación actual».

En el n. 5 leemos: Dios llama siempre a sus sacerdotes desde determinados contextos humanos y eclesiales que inevitablemente les caracterizan. El n. 6 enumera factores ambientales que favorecen la formación sacerdotal. El n. 7 describe aquellos otros que la dificultan. Los nn. 8 y 9 subrayan el impacto configurador que unos y otros producen. El n. 10 destaca la ambivalencia y el carácter en ocasiones contradictorio de estos rasgos de nuestra cultura. En un párrafo verdaderamente magistral que evita las descripciones dicotómicas tan socorridas en nuestros análisis eclesiales, aconseja un discernimiento evangélico sagaz. No se trata solo y simplemente dice el texto- de acoger los factores positivos y constatar abiertamente los negativos. Se trata de someter los mismos factores positivos a un cuidadoso discernimiento para que no se aíslen ni se contrarresten entre sí, absolutizándose y oponiéndose mutuamente. Lo mismo puede decirse de los factores negativos: no hay que rechazarlos en bloque y sin distinción, porque en cada uno de ellos puede esconderse algún valor que espera ser descubierto y reconducido a su plena verdad. Este prudente consejo de la Exhortación sintoniza con la afirmación de la sabiduría humana: casi siempre el bien lleva adherencias del mal y éste algún destello del bien.

Tiene su razón de ser el enfoque elegido. Albergo la certeza de que la incomprensión y la desconsideración de las claves de la cultura envolvente que respiramos producen efectos penosos en muchos sacerdotes. En virtud de la incomprensión, algunos se cierran crispadamente ante ella. No llegan a distinguir el trigo de la cizaña en el campo ambivalente del mundo (cfr. Mt 13, 29). Viven abatidos ante una deriva (ciertamente preocupante) que les resulta desconcertante y cerradamente negativa y alimentan ante ella resistencias agresivodefensivas.

Correlativamente, en virtud de la desconsideración, otros digieren sin el debido discernimiento una sensibilidad ambiental dominante que va debilitando paso a paso sus convicciones y opciones evangélicas. El conocimiento empático y crítico de nuestra cultura y el reconocimiento de su impacto en nosotros, son condición de una vida sacerdotal sana y centrada. 


\section{Abrir pistas en un bosque inabarcable}

Los grandes psicólogos de la personalidad humana reconocen su carácter inabarcable. Los instrumentos de aproximación y exploración quedan clamorosamente cortos. La amplitud y la complejidad del psiquismo humano les desborda. En este bosque inabarcable solo es posible abrir unas pistas.

La dirección en que se abren estas pistas no puede ser arbitraria. Algún criterio ha de guiarnos en esta labor. El criterio debe ser el ya marcado por OT, 4, recogido y comentado por PDV, 57 con estas palabras: La finalidad pastoral asegura a la formación humana, espiritual e intelectual algunos contenidos y características concretas, a la vez que unifica y determina toda la formación sacerdotal. La formación humana ha de orientarse, pues, hacia la formación del pastor. En su día, el card. Pío Laghi recogía autorizadamente el espíritu de PDV: La Exhortación propone un modo muy preciso de coordinar la formación. Esta debe tener como fundamento la formación humana; como corazón, la espiritual; como instrumento, la intelectual; como finalidad, la pastoral.

\section{EL IMPACTO SOCIOCULTURAL: OPORTUNIDADES Y DIFICULTADES}

El espacio de la conferencia me obliga a ser sobrio en la elección de los rasgos. Podrían elegirse otros igualmente característicos de nuestra cultura actual. Me remitiré a describirlos escuetamente, a desvelar su repercusión en nuestra vida y ministerio y a sugerir algunas pautas para potenciar las oportunidades y para superar (es decir, asumir, decantar y trascender) las dificultades que nos ofrecen.

\section{Cultura y narcisismo}

Según analistas acreditados, toda cultura segrega, entre otros, un tipo de personalidad que, interiorizando algunos de sus elementos destacados, subraya particularmente sus desviaciones. A principios de siglo, cobra relieve la personalidad histérica, estudiada por el psicoanálisis. En la época de la guerra europea del 39 , se genera la personalidad autoritaria que tiene su auge en el régimen nazi. En la posguerra, emerge con fuerza la personalidad depresiva, caracterizada por el oscurecimiento del sentido y el debilitamiento de la voluntad de vivir. En la actual sociedad postindustrial y postmoderna, florece la personalidad narcisista. 
a) Apuntes descriptivos

Prevalece una visión muy negativa del narcisismo. Es la única enfermedad que el hombre debería temer realmente, llega a decir A. Paoli. No es exactamente ésta la posición de una importante corriente psicoanalítica que, aunque considera patológicos los excesos y deformaciones del narcisismo en la sociedad actual, lo estima en sí mismo necesario para estructurar un yo sólido que sea capaz de regular, por un lado, los impulsos eróticos y agresivos humanizándolos y, por el otro, las exigencias rigoristas y culpabilizadoras que amenazan la alegría de vivir. Este yo no es ni pura razón, ni pura voluntad. Es también afecto y amor a sí mismo. En este sentido, el yo tiene un notable componente narcísico. Si fuera pura razón y pura voluntad no sería capaz de tener a raya los impulsos y exigencias antedichos, que son de carácter pulsional. Las ciencias humanas han recuperado este narcisismo genuino bajo la rúbrica de la autoestima, necesaria para la propia salud psíquica y para entablar relaciones no dependientes ni posesivas ${ }^{3}$.

Todo va bien hasta aquí. Pero es innegable que, en nuestra cultura actual, este narcisismo genuino se ha desbordado caudalosamente. El amor narcísico se ha curvado intensamente sobre sí mismo y ha perdido vigor y frescor para abrirse a un amor a otras personas, comunidades y causas. Se le denomina técnicamente narcisismo secundario. Quien lo padece es un perpetuo mendigo de amor, de aprecio, de elogio, de admiración acrítica. Un mendigo perpetuamente insatisfecho. Considera siempre insuficiente y deficiente el amor que recibe. Ata a las personas porque teme perderlas. Teme tanto perderlas porque en el fondo duda de que sea digno de su amor.

Si la personalidad narcisista se sitúa así en el registro del deseo, se sitúa análogamente en el registro del proyecto. Para compensar el déficit de seguridad en sí mismo, busca con encendida intensidad su propia realización personal. Solo cuenta su proyecto... o su sueño. Los vínculos objetivos de solidaridad con las personas o la comunidad no tienen peso vital en él.

b) Posibles repercusiones en la vida presbiteral

Perteneceríamos a otra galaxia si no registráramos el impacto de

3 LAPLANCHE-PONTALIS: «Diccionario de Psicoanálisis». Barna, 1971. Labor, págs. 238-242. 
este clima cultural. En efecto, todos conocemos, junto a sacerdotes que muestran un admirable desarrollo del registro de la oblatividad, otros perpetuamente insatisfechos que no se sienten suficientemente aprecia-dos ni por la comunidad, ni por el presbiterio, ni por el obispo. Las expectativas que depositan en estas instancias son desmedidas. Les exigen respuestas afectivas y efectivas que no pueden dar. Son los eternos incomprendidos.

Conocemos asimismo a presbíteros que invierten en su realización personal la mayor parte de su capital afectivo. Realizar estudios brillantes en lugares renombrados, ocupar puestos relevantes, adquirir notoriedad en los MCS, son algunas de sus ambiciones, maquilladas de nobles ideales.

No son excepcionales, pero sí un tanto extremos, los casos apuntados. El narcisismo se revela en niveles más modestos en otros muchos. La necesidad de singularizarse en su trabajo, la dificultad de adaptarse a proyectos compartidos, el personalismo con ribetes autoritarios en las decisiones pastorales, la hipersensibilidad ante la crítica, la resistencia a tomar decisiones evangélicas necesarias por temor a perder el aprecio de algunos, el cuidado excesivo por la propia imagen física o social, pueden ser algunos indicadores de un narcisismo de menor intensidad.

\section{c) Algunos recursos}

- No hay mejor camino para dejar de sentirse víctima que acercarse a las víctimas de verdad, afectadas por la pobreza, la enfermedad, la pérdida violenta de seres queridos, las graves carencias afectivas, la marginación de los débiles en esta sociedad competitiva, las heridas de un amor engañado y humillado. Pero no basta acercarse; es necesario empatizar e implicarse. Esta terapia de choque suele resultar efectiva en los afectados por una tasa no exagerada de narcisismo. Los ejemplares extremos resisten indemnes incluso esta inmersión terápica. La formación seminarística debería reservar tiempos de especial intensidad para acercarse en vivo y en directo a estas víctimas de verdad.

- Muchos de nuestros hábitos de comportamiento suelen estar inspirados por unas expectativas no elucidadas que nos gobiernan casi inconscientemente. La expectativa implícita a la que tiende el narcisista en la relación con cualquier comunidad a la que pertenece (parroquia, presbiterio, familia, grupo amical o cultural), puede formularse así: ¿Qué me aporta a mí la comunidad? ¿Qué bienes y satisfacciones puedo esperar de ella?» Nada avanzaremos mien- 
tras no se produzca en el sujeto una verdadera inversión por esta otra expectativa: ¿Qué puedo yo aportar a mi familia, a mi comunidad eclesial, a mi presbiterio, a mi barrio? Esta inversión es más difícil cuanto más tardía. Pero sigue siendo necesaria y posible. Es la única coherente con la pro-existencia requerida por el ministerio apostólico.

Dos surcos habrían de ser trabajados especialmente para superar el narcisismo: la aceptación del principio de la realidad que sabe distinguir en cada momento lo realmente posible de lo deseable y la oblatividad bien entendida (sin idealismos utópicos), bien motivada, bien acompañada y ejercitada.

\section{Cultura y erotismo}

a) La «explosión sexual» (A. Berge $)^{4}$

Llamada también liberación sexual, es una de las señas de identidad de nuestra cultura. Es la única revolución que ha triunfado. No vamos a describirla con detenimiento. Solo vamos a enumerar sus etapas principales: primero aconteció la ruptura entre la sexualidad y el matrimonio. Este no podía ser el único espacio legítimo para ejercitar la sexualidad. Reducirla a ese área restringida favorecía la obsesión y la violencia sexual. Más tarde se produjo la disociación entre sexualidad y procreación. El perfeccionamiento de los métodos anticonceptivos fue determinante. Quedaba un tercer paso. La disociación entre sexualidad y amor. El intercambio sexual se separa del compromiso del amor y deja de ser expresión del amor.

No vamos a negar que la liberación sexual ha barrido tabúes represivos, ha naturalizado la relación entre los sexos y ha propiciado la desapa-rición de un rigorismo moral insano y poco evangélico. Podemos, con todo, preguntarnos si no ha sido para muchos portadora de una nueva esclavitud, una banalización de la sexualidad y una necesidad de colmar con la multiplicación de las experiencias el vacío creado por un intercam-bio sexual plano, sin profundidad.

\section{b) El erotismo ambiental}

Uno de los grandes efectos de la explosión sexual es el fenómeno social del erotismo ambiental. Circula en la atmósfera una multitud ingente de estímulos eróticos que mantienen a muchos humanos en

4 BERGE, A.: «La sexualité aujourd'hui». París 1970 CASTERMANN. 
una alerta sexual casi permanente, es decir, en un nivel de excitabilidad desmedida. Las imágenes eróticas se multiplican en la calle, en la TV, en Internet. La publicidad pretende erotizar los objetos deseables vinculándolos a un fuerte estímulo erótico.

Esta multiplicación de estímulos digeridos, crea con frecuencia una fijación erótica (adicción) que provoca regresiones psíquicas a estadios arcaicos de la evolución sexual y facilita conductas compulsivas que propician la violencia en el ejercicio sexual.

El erotismo ambiental reinante no solo estimula las pulsiones sexuales, sino que concentra en torno a ellas toda una constelación de energías psíquicas. Muchas fuerzas que pudieran desplegarse en proyectos sociales, en realizaciones estéticas, en rendimiento laboral, en compromisos religiosos, son succionadas por el polo sexual. Se crean necesidades nocivas. Se descompensan comportamientos que habían logrado un equilibrio. Se aflojan los mismos criterios y actitudes morales. En este contexto prevalece la idea de que la vida célibe o bien es imposible o bien provoca en sus adheridos la denostada trilogía: tristeza, rareza, dureza.

\section{c) La vida célibe en este contexto}

Una persona tempranamente inmersa en este ambiente erótico, experimenta mayores dificultades para la continencia sexual, presupuesto necesario de una existencia célibe. No puedo aducir estudios rigurosos, pero tengo la fundada impresión de que, por ejemplo, liberarse de la servidumbre autoerótica resulta hoy a las generaciones presbiterales, sobre todo jóvenes, más costoso que en épocas anteriores. El cambio drástico de las costumbres sexuales ha rebajado sensiblemen-te la calificación moral espontánea que tales costumbres nos merecen. ¿El rigorismo anterior ha sido sustituido en bastantes casos por una conciencia laxa o perpleja?

La experiencia de trato profundo con muchos sacerdotes me ha conducido a la convicción de que en las actuales circunstancias erotizantes, un porcentaje nada insignificante de presbíteros viven el celibato con generosidad incluso elegante. En otro porcentaje mayor, el celibato es un intento honesto y un logro aceptable. Otro grupo nada desdeñable vive su condición célibe con una notable tasa de ansiedad e insatisfacción y con alternancias en su conducta. Existe, en fin, un grupo de presbíteros que han tirado la toalla y se encuentran más o menos incómodamente instalados en la doble vida. 


\section{d) Para aprender el lenguaje célibe del amor}

Mientras el clamor en torno a la vida sexual es tan intenso, la palabra no ha cobrado todavía ni el espacio ni la calidad necesarias en el mundo presbiteral. Hay menos silencio que hace 25 años, pero aún queda demasiado silencio. Sin duda, se ha avanzado a la hora de ofrecer una más adecuada visión antropológica, teológica, espiritual y pedagógica del celibato. A pesar de ello nos enfrentamos más bien solitariamente y no demasiado equipados a las sucesivas evoluciones y crisis que van produciendo en nosotros el desarrollo y los cambios de nuestra sexualidad y afectividad5. No me parece recomendable el intercambio verbal de nuestra intimidad en el seno de un grupo. Pero caben comunicaciones y reflexiones conjuntas que lleven al marchamo de la seriedad, la profundidad y la verdad.

La transparencia ante un testigo cercano, respetuoso, libre y capaz de una escucha cualificada, resulta saludable para todos y necesaria para muchos. Ni el pudor, ni el orgullo, ni la dificultad de encontrar este testigo deben dispensarnos de este ejercicio. Los impulsos y los afectos se humanizan y se sosiegan sensiblemente cuando pasan al registro de la palabra. La comunicación sencilla como el agua clara, no envuelta en la cobertura del lenguaje técnico, tiene un efecto sanante y liberador. A mi parecer, estamos ante una carencia notable que está en el origen de muchos deterioros lamentables.

El amor célibe es una entrega. Nadie se entrega del todo y de por vida a dogmas impersonales ni a causas morales. Nos entregamos a personas: al Señor Jesús, Buen pastor, con un amor de identificación y a la comunidad con un amor de servicio. Son ellos quienes merecen y demandan que condensemos nuestra capacidad de amar en el surco de la filiación y la fraternidad.

En tiempos de sobrecarga erótica ambiental, el amor célibe postula especialmente una ascesis de sobriedad ante los estímulos que pueden complicar innecesariamente la vivencia del celibato.

\section{Cultura y pertenencia}

Uno de los fenómenos destacados por los analistas de nuestra cultura (p.ej. P. Berger) es la fragmentación y el debilitamiento de la pertenencia.

5 GARCÍA, J.A., En torno a la formación: cinco hipótesis de trabajo, en «Sal Terrae», diciembre de 1990. 


\section{a) El sentido de pertenencia}

Maslow, gran psicólogo humanista norteamericano, incluye el sentimiento de pertenencia entre las seis grandes necesidades vitales básicas de la persona. No sin razón: la pertenencia es un componente de la identidad. Uno no sabe quién es mientras no sabe a quién y a qué pertenece. Los estudios realizados con niños criados en una promiscuidad en la que no tienen clara referencia de quiénes son sus padres, resultan desoladores: la confusión y el marasmo son dominantes en su situación. Si queremos mantener entera nuestra salud mental, nuestras cinco o seis pertenencias fundamentales tienen que ser muy claras y muy sentidas: la familia, la comunidad humana próxima, el ámbito sociocultural del que formamos parte, la humanidad, la comunidad eclesial local y universal, Dios. Los creyentes no podemos olvidar, además, que el sentido de pertenencia es un componente humano básico de la comunión, alma de la comunidad eclesial. La Congregación para la Educación Católica acaba de anotarlo en su último documento ${ }^{6}$.

Estos son los caracteres mayores del sentido de pertenencia:

- es recíproco: aquel o aquellos a quienes pertenezco, me pertenecen también a mí

- es creador de empatía entre los miembros que pertenecen a la misma comunidad

- genera adhesión comunitaria: asumimos la historia de ésta con sus páginas luminosas y sus pasajes oscuros. Nos sentimos solidarios de sus grandezas y sus miserias, afectados por sus logros y sus crisis. La comunidad es estimada. Valoramos mucho pertenecer a ella.

- se alimenta de experiencias comunitarias reales y simbólicas de comunión. Convivir, concelebrar, colaborar y compartir son los cuatro verbos generadores del sentido de pertenencia.

\section{b) La crisis del sentido de pertenencia}

La vida parcelada y fragmentada, hoy tan común, contribuye a la fragmentación del sujeto y al debilitamiento de sus pertenencias diferentes. Aquellas comunidades o colectivos más amplios, con los cuales la relación de la persona es menos intensa y más densamente institucional, son las primeras que se resienten. El sujeto se

6 CONGREGACIÓN PARA LA EDUCACIÓN CATÓLICA: «Orientaciones para el uso de las competencias de la psicología en la admisión y en la formación de los candidatos al sacerdocio». Editrice VATICANA 2008, n. 2. 2. 
adhiere más fácilmente a microgrupos más próximos en los que encuentra calor y afectividad. Es débil y quebradiza su adhesión a grupos que le trascienden espacial y temporalmente. El desapego institucional es un fenómeno frecuente y creciente.

Con todo, los especialistas ven en este fenómeno preocupante unas raíces más nobles y válidas. Sería la contrapartida dialéctica del descubrimiento del sujeto individual realizado en la modernidad, cuyo reflejo y resultado más tangible es la Declaración Universal de los Derechos Humanos (1948). Estaríamos en un momento de antítesis. Es deseable y necesario un movimiento de síntesis. El pensamiento social cristiano apunta explícitamente en esta dirección. Tal síntesis es cohe-rente con la estructura del ser humano, a la vez individual y social.

Es cierto que la fuente específica de esta crisis es la fragmentación de la época postmoderna. Pero justamente por el carácter recíproco del senti-do de pertenencia, el carácter frío, lejano, duro de las grandes institu-ciones favorece el desenganche vital de las personas. Si añadimos que en la pobre relación entre el sujeto y el gran grupo se interponen los MCS, el individuo vive no solo una relación mediada, sino muchas veces deformada por ellos.

\section{c) Pertenencia y vida presbiteral}

También este fenómeno cultural está afectando al mundo presbiteral. Es bien conocida la retracción que experimentan respecto de la vida diocesana muchos sacerdotes a partir de su jubilación. Según los expertos en gerontología, las tres crisis de las personas mayores afectan a su identidad, a su autonomía y a su sentido de dependencia ${ }^{7}$. Todavía los ancianos no tienen un lugar social suficientemente reconocido. El caso es sensiblemente más suave en la Iglesia. Pero también en ella muchos sacerdotes mayores se sienten al margen de la corriente de la vida eclesial. Esta marginalidad, favorecida también por la propia dinámica del anciano, provoca de su parte cierto desentendimiento y una regresión a su mundo interior.

Pero la crisis del sentido de pertenencia se extiende también a otras generaciones sacerdotales. La polarización en la comunidad parroquial y la distancia psíquica respecto de otras pertenencias eclesiológicamente muy consistentes (la iglesia local), no es un fenómeno

7 LAFOREST, J: «Introducción a la gerontología». Barna 1991. Herder. 
residual. Según mi limitada experiencia, las generaciones más jóvenes no parecen escapar a este movimiento centrífugo. Tampoco las generaciones intermedias son del todo ajenas a él. Una mejor teología de la iglesia local favorece, pero no crea sin más, sentimientos de pertenencia. Tenemos que discernir qué es, en este punto, cultural y qué es debido a deficiencias formativas pasadas y presentes y a carencias de reciprocidad por parte de la diócesis. La atención personal a cada sacerdote en tiempos de intemperie, la buena socialización de los proyectos e iniciativas diocesana, la ayuda eficaz en momentos de dificultad (económica, sanitaria, existencial), son puntos para el examen de conciencia de los responsables.

No quiero eludir una expresión de esta crisis que afecta a la relación de bastantes presbíteros con la Iglesia Universal. Es innegable que la figura del Sucesor de Pedro es, en el nivel real y simbólico, generador necesario y eficaz de un sólido sentimiento de pertenencia eclesial. La comparación con otras iglesias y confesiones cristianas evidencia la hondura y el valor inestimable del servicio del Primado. Sucede que la fragmentación de la vida y la frialdad de las grandes instituciones, tienen también su reflejo no solo en la pluralidad de pensamiento teológico y pastoral, sino en la tensión de alto voltaje que, al menos en algunos medios eclesiales y presbiterales, se vive respecto a ámbitos amplios que trascienden los límites de las diócesis. Esta tensión llega a rebajar notablemente el crédito moral de los pastores no solo ante la sociedad, sino ante los mismos feligreses. Hace sufrir a muchos sacerdotes que estiman que dicha tensión no es simplemente fruto de movimientos centrífugos», sino propiciada también por centralismos no exentos de ideología.

El sentido de pertenencia puede, en fin, exclusivizarse en algunos presbíteros. Una sensibilidad sacerdotal debe articular bien las pertenencias seculares y las eclesiales. Aquella que vive muy pendiente de la Iglesia y de sus vicisitudes (a veces también de las intrascendentes) y bastante indiferente a la sociedad, es más eclesiástica que eclesial. No hemos de ser mundanos, pero sí seculares. Aquella otra muy atenta a los avatares de la sociedad y poco sensible a los intentos y tropiezos de su Iglesia que formula a veces con la expresión a mí me interesa el Reino, no la Iglesia, está lejos de ofrecer la debida consideración a quien es signo e instrumento de este Reino y el debido amor a una comunidad que, con todas sus limitaciones, le ha transmitido la memoria viva de Jesús y la fe en Él. No podemos menos de amarla cordialmente y sentirnos vinculados a su presente y su futuro. 


\section{Cultura y confianza básica (E. Erikson) ${ }^{8}$}

\section{a) Un déficit paradójico}

Las altas metas logradas por el hombre en el conocimiento y dominio del mundo y en la consecución de la salud y el bienestar, provocan en él un sentimiento colectivo de autosuficiencia. A primera vista, este sentimiento colectivo debería reforzar su seguridad subjetiva y existencial. Paradójicamente, no parece ser este el efecto producido por tantos éxitos humanos. Prometeo tiene los pies de barro. Psicoanalistas de renombre mundial creen descubrir en el fondo endotímico de las actuales generaciones un déficit de confianza básica, una inseguridad radical, una extraña combinación de intensa ambición y de fantasías grandiosas, sentimientos de inferioridad, excesiva dependencia de la aprobación, insatisfacción respecto de sí mismo (Kernberg) ${ }^{9}$. Me atrevo a añadir: la sensación de no estar asentados en un fundamento firme y el temor a un futuro incierto. Parece faltar un punto de apoyo originario y un punto de proyección hacia el futuro. La inseguridad propia y la dificultad de confiar en el Otro y en los otros van emparejadas en este síndrome de la desconfianza básica.

No tengo espacio ni competencia para explicar las causas de este déficit, pero sí la suficiente experiencia para detectar las raíces tempranas, educativas, actuales de este déficit. Winnicot se inclina por fallasarcaicas en la relación del niño con la madre. La crisis de estabilidad de la pareja pasa probablemente factura a los hijos nacidos de ésta. Me pregunto si la fe en Dios no ha ofrecido a muchos en el pasado una persuasión de estar asentados, acompañados, acogidos. El déficit de esta experiencia agravaría la carencia señalada. Podemos tal vez entrever algunos de sus efectos. La falta de confianza básica puede erosionar la mutua confianza de la pareja o afectar a la estabilidad del amor compartido. Tal estabilidad viene condicionada seriamente por la inseguridad existencial. Puede estar en el origen de ciertos insomnios (cuesta entregarse al sueño). Puede deteriorar otras relaciones humanas tiñéndolas de actitudes suspicaces o hipersensibles. Puede dificultar la entrega confiada a Dios.

8 ERIKSON, E.: Infanzia e societá. Roma 1967. Armando.

9 KERNBERG, B.: «Conditions and Pathological Narcissisme» (citado por A. Cencini en Por amor, con amor, en el amor. Madrid, 1996, pág. 162. 


\section{b) Confianza básica y vida presbiteral}

Varios síntomas podrían delatar en bastantes sacerdotes este déficit tan fundamental. El primero sería la ansiedad intensa que nos acompaña en nuestra vida y trabajos. Estaría provocada por la incertidumbre de conseguir aquello que deseamos obtener. A la persona ansiosa le cuesta mantener la paz interior. Su ansiedad se refleja en la prisa, muchas veces inmotivada, que se apodera de él. La prisa le vuelve impaciente.

El segundo síntoma podría ser la hiper-responsabilidad. El hiperresponsable no se fía en el fondo de que las cosas se harán si él se desentiende de ellas. Le cuesta mucho desconectar. La responsabilidad le persigue. Más en el fondo, no acaba de creerse que quien salva es Dios y solo Dios. La hiper- responsabilidad conduce directamente a la hiperactividad que nos pone nerviosos a nosotros y a nuestros colabora-dores. Nos quita el sosiego para escuchar a la gente... y a Dios. La hiper-responsabilidad es la patología de los responsables inseguros.

Las personas inseguras sienten la aguda necesidad de ser confortadas por seguridades exteriores. Soportan mal los tiempos de cambio cultural y eclesial. A veces se aferran a un universo de seguridades y a grupos eclesiales cálidos que se las ofrezcan. Debajo de esta adhesión más o menos crispada, se alojan, en mayor o menor medida, la inseguridad y el miedo.

\section{c) Aprender a confiar}

Una respuesta válida a este subtítulo requeriría ahondar en los factores que generan el déficit de confianza. Confieso que no he podido realizar este trabajo previo con la suficiente hondura.

Ciertamente, puesto que esta inseguridad es, ante todo, de carácter afectivo, cuidar la relación rica en familiaridad con estos presbíteros, mostrarles aprecio por su persona y su trabajo son comportamientos que alivian un tanto sus tensiones interiores.

Tiendo a pensar que el mayor servicio que pueden prestarse y podemos prestarles es la profundización de su experiencia creyente. Ella nos conduce, por encima de nuestros miedos y resistencias, a fiarnos a fondo perdido de Dios. Ella nos hace sentir que en el origen está Él, Fundamento que no falla (Dios es mi roca, dirá el Antiguo Testamento). Que en el camino, Él es el compañero de viaje que nos acompaña incluso en el valle oscuro de las tinieblas (cfr. Salmo 23, 4). Que el final está Él, acogiéndonos, salvándonos de la 
nada, llevándonos a la plenitud. Estaremos siempre con el Señor (1 Tes 4,17$)$. Estoy convencido de que esta fe sentida ha contribuido a engendrar en una inmensa muchedum-bre de creyentes una confianza que ha vencido al miedo. Si yo he sido amado, no necesito buscar ni conquistar (ansiosamente) signos de afecto. Si yo he recibido tanto, puedo y debo preocuparme de dar. Me puedo fiar'10.

\section{RESORTES BÁSICOS}

PARA UNA ADECUADA FORMACIÓN HUMANA

Las indicaciones particulares apuntadas a lo largo del segundo capítulo han de completarse con algunas otras de carácter más básico y englobante.

\section{Asumir la propia historia}

Si hay una verdad que la psicología clásica ha asentado incontestablemente, es esta: para orientarse positivamente hacia el futuro, el pasado debe ser asumido11. El pasado que no asumimos se convierte en un segmento suelto y perturbador que irrumpe en nuestro presente y altera nuestra proyección al futuro. Quien no asume el pasado está condenado a repetirlo. Las neurosis no son sino bloques relativamente autónomos respecto del yo, producidos por represiones precoces que hostigan crónicamente al sujeto y le roban una preciosa energía psíquica para construirse bien.

Asumir el pasado significa integrarlo en la persona, reconociendo y valorando su herencia positiva, neutralizando su carga negativa y extrayendo de ambas, lecciones para el presente y el futuro. Sin esta anamnesis saludable, no acabamos de saber quiénes somos. Uno se reconoce en el contexto de su propia historia. Es muy importante, sobre todo, identificar y liberarnos de nuestras emociones negativas no asumidas: rechazos, miedos, resentimientos, culpabilismos, etc. ${ }^{12}$

No es fácil esta lectura de nuestro pasado. Llevamos dentro de nosotros resistencias para reconocer episodios penosos o desacertados: La memoria me dice: has obrado mal; el orgullo me dice: no has podido

10 CENCINI, A.: «Los sentimientos del hijo». Sígueme, Salamanca 2003.

11 VERGOTE, A.: «Psychologie religieuse». Bruselas 1966. Dessart, pág. 220.

12QUINZÁ, X.: «Modular deseos, vertebrar sujetos». Madrid 2005. San Pablo, págs. 166 ss. 
obrar mal; y el orgullo acaba acallando a la memoria (Nietzsche). No resulta sencillo soportar la verdad sobre sí mismo.

Correlativamente, una situación depresiva puede impedir la valoración positiva que merecen episodios y capítulos de nuestra historia. En tal caso, la lectura tenebrista de nuestro pasado se vuelve una tentación a veces insuperable.

En virtud de estas dos actitudes previas, podemos quedar fijados en una lectura selectiva de nuestro pasado que no resulta liberadora. En cambio, cuando esta lectura se hace bien, determinados acontecimientos o situaciones negativas son interpretadas como oportunidades positivas para el presente. Me estuvo bien el sufrir; así aprendí tus mandatos (Salmo 118, 71).

Todos los aspectos importantes de nuestra vida han de ser elucidados por esta mirada sagaz y cariñosa a nuestro pasado. Por supuesto, también a nuestro pasado religioso y moral. San Agustín en sus Confesiones y San Ignacio en su Autobiografía, nos han regalado un admirable reconocimiento retrospectivo. La fe nos ayuda a ello en un movimiento en el que se combinan simultáneamente el reconocimiento del pecado y la confianza en una Misericordia infinita.

Asumir el pasado es tarea permanente. Pero resulta especialmente saludable cuando, pasados unos años de ministerio, estamos en disposición de realizar un balance global. A mi entender, el año sabático al que todos los sacerdotes deberíamos tener acceso, es un espacio privilegiado cuyo primer objetivo, antes de cualquier actualización, debería consistir en esta lectura retrospectiva. Cuando se realiza suele curar heridas, deshacer bloqueos, liquidar facturas pretéritas, propiciar un nuevo comienzo. Unos Ejercicios Espirituales de mes entero suelen resultar, cuando nos son posibles, un excelente complemento. Sorprende que sean tan pocos los sacerdotes que deseen y pidan tiempo sabático y los obispos que lo faciliten y lo propongan con fuerza persuasiva. La pereza y los temores de los unos y las urgencias inmediatistas de los otros son explicables, pero no razonables.

Esta asunción del pasado necesita ser acompañada. No basta para ello la introspección solitaria, por penetrante que sea. Es preciso decir este pasado ante otro. No es preciso que ese otro sea un especialista. Sí ha de ser una persona lúcida, respetuosa, libre, familiarizada con la sabiduría de la comunicación y con las vías del espíritu. Su principal tarea consiste en propiciar una lectura verdadera que identifica los puntos luminosos, reconoce errores y debilidades, descubre potencialidades de crecimiento incluso a partir de capítulos negativos, y ayuda a descubrir, desde la fe, el sentido global de nuestra trayectoria vital. 


\section{Garantizar el equilibrio entre interioridad y exterioridad}

Las ciencias humanas nos han ayudado a distinguir mejor, dentro del comportamiento humano, su cara externa (la conducta) y su cara interna (la vivencia). Dentro de este marco de comprensión, interioridad y exterioridad, más que dos capítulos de actividades diferentes son dos dimensiones de todo comportamiento verdaderamente humano.

Estas dos dimensiones han de guardar en la vida de los presbíteros una real armonía. Cuando se desequilibran sensiblemente, descompensan la totalidad psíquica de nuestra vida. El equilibrio entre ambas es signo y condición del crecimiento humano. La interioridad desconectada de la exterioridad acaba sofisticando la visión de la realidad, complicando lo sencillo y simplificando lo complejo, hipertrofiando la sensibilidad y convirtiendo los problemillas en problemazos. La exterioridad insuficientemente enriquecida por la interioridad, resbala sobre los asuntos. El sujeto se vuelve incapaz de una reflexión sosegada y especialista en profundizar en la superficie.

Me parece que en una notable porción de presbíteros, el equilibrio se descompensa a favor de la exterioridad. No es la actividad intensa, sino el activismo, uno de los mayores desequilibradores. El activismo no es sin más una actividad excesiva, sino una actividad pobre en interioridad. Propiciada por una agenda demasiado cargada, unos horarios descoyuntados, una escasa afición introspectiva y un pobre hábito de reflexión, va provocando en el sacerdote una impaciencia crónica que lo va tornando incapaz de escuchar con sosiego, de preparar a conciencia sus intervenciones, de leer con atención concentrada y prolongada, de orar con detenimiento.

Pero no es el activismo el único enemigo de la interioridad. Muchos sacerdotes infraocupados pastoralmente patinan fácilmente en las pistas de la exterioridad. Sus horarios demasiado holgados, lejos de estimularles a profundizar, les sumen en una pereza crónica o les inducen a llenar el tiempo en ocupaciones de escaso calado interior. Los instrumentos electrónicos, hoy tan al alcance, saben mucho de estas ocupaciones. Una tasa de actividad no desmesurada es, en principio, más estimuladora de la interioridad que un ritmo apagado. Favorece más la necesidad y la búsqueda.

No veo otra vía para recuperar el equilibrio perdido que introducir en el ritmo de la vida actividades que conlleven una exigencia mayor de interioridad: la reflexión teológica y pastoral, las lecturas sosegadas y bien escogidas sobre otros temas humanos (novelas, teatro), la comunicación de la propia intimidad, la amistad, la relación con la naturaleza, la escu- 
cha de buena música, la contemplación estética, la oración prolongada. Si para incorporarlas es necesario un drástico parón en nuestra vida, hemos de estar dispuestos a llevarlo acabo y a favorecerlo.

\section{Una buena dialéctica entre la persona y su rol}

No es de recibo la teoría según la cual el ejercicio de un rol empobrece a la persona robándole sensibilidad, libertad. El cargo y la responsabilidad inherente a él pueden y suelen, con frecuencia, favorecer una mayor consistencia personal. El rol paterno o materno ha ayudado a madurar a muchas personas y parejas aún no suficientemente consolidadas. No existe, pues, una antítesis, sino una polaridad dialéctica entre persona y rol. Eso sí: cuando éste es fuerte y público y la persona es insegura y pusilánime, el rol puede ahogar a la persona.

El cargo sacerdotal es un cargo de confianza. La Iglesia confía al presbítero su tesoro más valioso: la Palabra, la Eucaristía, la Reconciliación sacramental, la comunidad, los pobres. Un cargo de confianza genera de ordinario autoestima, capacidad de decisión, aguante, voluntad de aprender. En otras palabras, refuerza a la persona.

El cargo sacerdotal es un cargo público. Si la personalidad del presbítero es débil, puede producir una polarización y un endurecimiento en torno al rol. El sacerdote -dice el car. Martini- corre el peligro de subirse sobre su propio rol para hablar y actuar desde allí sin preocuparse de estar en sintonía con el camino de su gente y sin intuir lo que (legítimamente) esperan de él, estableciendo una comunicación más aseverativa que dialogal, más repetitiva que creativa, más circunspecta y precavida que explícita y cordial.

Si el exceso de rol conduce a esta calcificación del sacerdote, el defecto en la conciencia del mismo puede deteriorar su actitud representativa. Representar es algo más que presentarse. Es presentarse como alguien dotado de una significación que trasciende su propia persona. Cabe una sobre-representación que no sabe quitarse el alzacuello en ámbitos de relación privada, familiar, amical. Pero suele darse también una infra representación que olvida la condición de signo cualificado que lleva consigo su persona.

Cuando la comunidad instituida a la que representa es contestada o ignorada, el déficit de representación se insinúa como una tentación poderosa. El sacerdote expone opiniones personales, adopta conductas externas poco coherentes con lo que legítimamente se espera de él, se empeña en ser uno más en la comunidad que preside y de la que forma parte. Cuando en una homilía escucho expresiones como a mí me parece 
que..., me pregunto si este presbítero sabe en nombre de quién está hablando en la celebración litúrgica. Naturalmente, aunque somos voz de la Palabra, esta voz tiene su tono, su timbre, su modulación diferenciada. Quien quiere eliminarse como sujeto para ser en manos de Dios un instrumento (inerte), no es un mensajero sino un disco. Creyendo haber eliminado los registros personales y subjetivos, éstos harán irrupción de modo inconsciente en su predicación ${ }^{13}$. Pero no solo un lenguaje repetitivo, esclerotizado, es lesivo a la Palabra de Dios. Lo es también un lenguaje pretendidamente actual, extraído de la jerga juvenil o alquilado al discurso cultural dominante ${ }^{14}$. Cuando el celebrante confunde naturalidad con espontaneidad y se permite alegrías que contravienen la dinámica de la acción litúrgica, está asumiendo un protagonismo que no le corresponde a él sino a Aquél a quien representa.

\section{CONCLUSIÓN}

Estas son las reflexiones que, a trompicones, he ido anudando en las pasadas semanas, con el ánimo de responder a lo que se me pedía. Están escritas con veneración a la figura, el mensaje y la obra de Mosén Sol, en esta señalada efemérides, y con afecto familiar a la Hermandad de Operarios Diocesanos, respecto de los cuales me precio de ser su amigo.

13 KLOSTERMANN F., El predicador del mensaje cristiano, en RAHNER K.HÁRING B. (eds.), Palabra en el mundo (Nueva alianza 32), Sígueme, Salamanca 1972, pág. 234.

14 CAMARERO, J: Ministro de la Palabra, en «Diccionario del Sacerdocio». Madrid 2005. BAC. 